\title{
Ignorancia, sometimiento, capitalismo a lo salvaje y perversión en el nacimiento y el seguimiento de la reforma neoliberal en salud
}

Ernesto A. Selva Sutter

Departamento de Salud Pública UCA, San Salvador

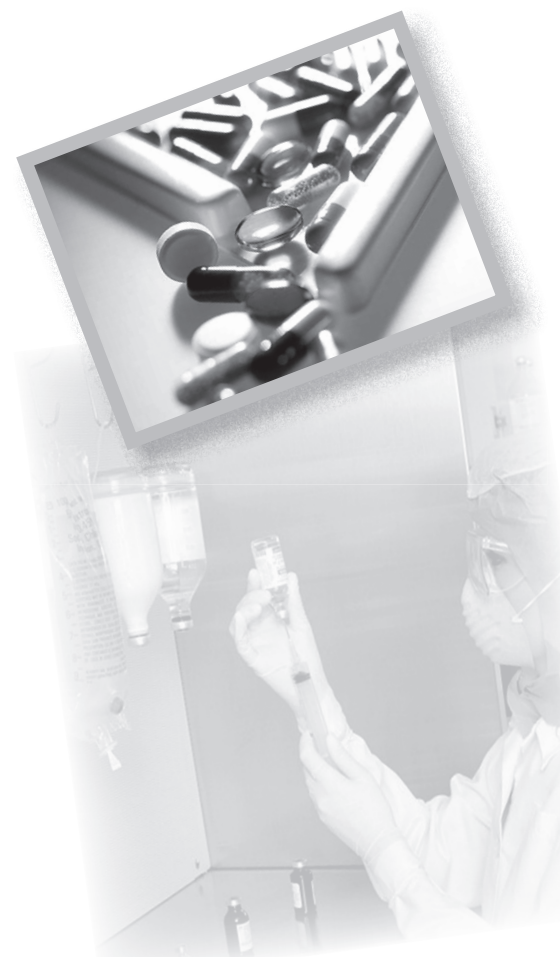

RESUMEN: En el presente trabajo se parte de la reforma del sector salud en El Salvador para comprender cómo el mercantilismo lleva a cometer auténticas aberraciones en el sistema de salud. Empero, este problema no se reduce a una determinada administración de gobierno: se remonta, más bien, a la escalada del neoliberalismo a nivel mundial. En virtud de ello, la salud, en sus más variados ámbitos, pasa a ser una mercancía entre muchas.

ABSTRACT: The following work starts analyzing the reform of the health system in El Salvador, in order to understand how mercantilismleads to commit clear aberrations in the health system. However, this problem is not reduced to a certain administration in the government: it is originated to the rise of Neo Liberalism worldwide. Due to this, health turns into a mere merchandise. 


\section{A manera de introducción}

$\mathrm{E}$ conjunto de aseveraciones que me dispongo a elaborar responde a la mezcla de ignorancia, subyugación voluntaria, quizás algunas veces involuntaria, capitalismo salvaje y perversión que podemos identificar en la mayoría de las diferentes propuestas, declaraciones y otro tipo de acciones que ocurren en nuestro medio alrededor de la problemática de salud en la que destaca el tema de reforma de salud.

En primer lugar, quiero dejar en claro que aunque la mayor parte de veces haré referencia en el texto a los documentos que respaldan mis aseveraciones, éstas están respaldadas, además, por más de cuatrocientas piezas de investigación y de reflexión publicadas en las revistas científicas de mayor prestigio en el área.

Segundo, es conveniente aclarar que toda opinión tiene cierto con- tenido ideológico y que las mías no son la excepción; pero, que la cuestión en el área científica es en qué proporción la ideología contribuye a la formulación de cada postulado, o, dicho de otra forma, ¿cuál de ellos está más fundamentado en hechos científicos que en creencias? Mis postulados tienen respaldo científico y mis creencias, explicaciones y expectativas acerca de la naturaleza del mundo están orientadas al bien común. Esta declaración es necesaria en atención a lo frecuente que es en nuestro medio que personas engreídas sin fundamento para ello, pretendiendo no estar ideologizadas, intenten desprestigiar los postulados de sus adversarios por su contenido ideológico, en su afán de defender, por ejemplo, el "sacrosanto" derecho que tiene la empresa privada de hacer negocio con todo, todos y todas, antes que proteger el derecho de todos los ciudadanos a la salud.

\section{2. ¿Es lo mismo Doña que Don Mercedes? ¿Es posible hacer buena medicina y salud pública sin cambiar el status quo económico-social?}

E

n tercer lugar, es virtualmente imposible exponer, discutir y, o entender la situación de salud del país si además de obviar lo obvio y de exigir explicaciones y "pruebas" exhaustivas hasta para lo evidente (pobreza extrema, enferme- dad de todo tipo, violencia también extrema, corrupción documentada, etc.), se recurre constantemente a múltiples intentos para confundir al público y engañarlo directamente (con desinformación, amarillismo, etc.) o por la vía de exponerlo a 
opiniones no autorizadas; más si toda propuesta exigida a toda persona que haga alguna crítica a las propuestas de reforma neoliberal que no venga de organizaciones internacionales o gubernamentales es descartada a priori, muchas veces en medio de llamados a desoír más opiniones y a proceder con la reforma de inmediato; lo que en realidad quiere decir hacer cualquier reforma que permita abrir el campo de la salud a intereses privados.

La salud pública ha sido víctima particular de estos abusos. Cualquiera se atreve a emitir opinión sobre el tema y a postular soluciones, y cuando digo cualquiera, me refiero a cualquiera, no únicamente a los profesionales de las ciencias de la salud entre quienes es más frecuente y arraigada esta práctica, y para muchos de quienes medicina y salud pública es virtualmente la misma cosa, tanto que una opinión muy difundida al referirse a futuros gabinetes de gobierno es "lo que no se discute es que el Ministro de Salud debe ser un médico"; frase que, aunque pueda encerrar alguna lógica en el sentido de que en nuestro medio el peso del médico en el ámbito de la salud es indiscutible, también deja al descubierto el fenómeno de la medicalización de la "salud pública" en El Salvador.

Sin embargo, se trata de dos ciencias diferentes, aunque para ser efectivas necesiten actuar en conjunto constantemente. Si la salud representa un proceso de constan- te tensión entre consolidación y cambio que exige un sustrato que favorezca la vuelta a la consolidación en términos de la realización de las necesidades de subsistencia, protección, afecto, entendimiento, participación, ocio, creatividad, identidad y libertad, y si para ello es imprescindible la interacción de tales valores realizados con acciones especializadas provenientes del sector salud, entonces, medicina y salud pública no pueden ser menos que aliadas.

De hecho, ya se ha señalado que el médico va por el mundo con un estetoscopio, mientras el salubrista va por el mundo con un denominador; que el médico y la mayoría de los demás profesionales y académicos de las ciencias de la salud centran sus esfuerzos en el nivel individual de intervención, en el cuerpo humano, intentando curarlo o aliviarlo, mientras la salud pública se ocupa más por indagar e intervenir también en los otros niveles - el medio ambiente inmediato y la estructura social- porque para prevenir la enfermedad y promover la salud es imperativo conocer todas sus determinantes. Incluso, ya se ha denunciado el indeseable cisma entre la medicina y la salud pública propiciado principalmente por la separación entre las escuelas de salud pública y las escuelas de medicina, a la vez provocada por los intereses del capital en los Estados Unidos, con el afán de poder hacer medicina y salud pública sin cambiar el status quo. 
Esta última idea, por supuesto, es, sin eufemismos, un ejemplo de carencia de entendimiento de los fundamentos de las ciencias de la salud, particularmente de la salud pública y de la medicina. Simplemente, porque, utilizando las palabras de Contandriopulos del grupo de Montreal, investigaciones recientes muestran que el estado de salud es influenciado de manera inequívoca por la posición social, cualesquiera sean los indicadores usados para medirla; porque, además, hay un gradiente entre la posición ocupada y la salud de manera que cuanto más alto se está en la jerarquía social, mejor salud se tiene'.

Porque, además, lo que impera en El Salvador y en el mundo es la desigualdad y lo que es peor, las iniquidades, las diferencias injustas, innecesarias y reversibles, cuya persistencia tampoco es inocua. Bezruchka reportó que ya en el año dos mil la iniquidad se traducía en unos catorce a dieciocho millones de muertes anuales, el $18 \%$ de las muertes anuales en el mundo, más de las que producen anualmente en el globo las infecciones respiratorias agudas (IRAS), diarreas, tuberculosis, SIDA y malaria juntas.

A esto se puede agregar otra verdad contenida en la propuesta de reforma de salud que presentara el equipo de asesores nacionales a la Asamblea Legislativa en el año 2005, consistente en que es una necesidad que la reforma sea precedida o acompañada por un esfuerzo conducente a proporcionar a toda la población: ingreso digno, agua potable, energía domiciliar, higiene, saneamiento y vivienda que de albergue, seguridad en el trabajo, seguridad alimentaria, seguridad en general y educación, porque no hay sistema de salud capaz de soportar la carga de enfermedad que sin tal esfuerzo se produce y la consiguiente carga económica que atenderla debidamente acarrearía.

Por supuesto, si gran parte de la población no se atiende como es debido y a otra se le atiende precariamente, pero se publicita que a ambas se les atiende de la mejor manera, es posible que algún sector de la población se engañe o se quiera engañar y que esto sea aprovechado por los defensores de la reforma neoliberal. Sin embargo, en esa ocasión hasta el asesor internacional contraparte apoyó la moción, porque no es defender lo social lo que es erróneo, radical, populista o inocente; porque, lo que es más bien perverso es señalar la grandeza del mal social, y como diría Roque Dalton, proponer soluciones de hormiga para intentar mantener el status quo.

Ningún asesor internacional que se respete puede discutir lo que el mismo Banco Mundial (BM) afirma. Primero, la íntima relación entre la pobreza y las altas tasas de morbilidad y mortalidad; segundo, la necesidad de atacar a la pobreza; y tercero, la enorme capacidad del sistema dominante de producir pobreza, a pesar de objetivos del mi- 
lenio y otras estrategias neoliberales de reducción de la pobreza, puesto que según las proyecciones de crecimiento demográfico y pobreza del mismo BM es posible sostener que casi el $80 \%$ de quienes sobrevivan la relación nacimiento-muerte al menos por los próximos 45 años serán pobres, porque la opción económica que tienen o tendrán es la de intentar subsistir con menos de dos dólares diarios. ¿lnnecesariamente apocalíptico como podría señalar algún "analista" local, pretendidamente moderado, que crea que así se va a congraciar con la derecha, con el BM y hasta con "la embajada?" ¡Rotundamente no! Los datos son confiables y el análisis de los mismos rigurosamente científico.

Más bien, la situación confirma el "principio de la locura", según Einstein, de "hacer lo de siempre y esperar resultados diferentes", o sea, como en el caso de implementar una tras otra estrategia de reducción de pobreza sin cambiar la estructura económico-social, persiguiendo mantener el status quo explotador, enpobrecedor y propiciador de iniquidades y por otra parte esperar la reducción de la pobreza o el logro de los objetivos del milenio. ¡Guste o no, los cambios estructurales son obligados!

Retomando el tema de la dialéctica de la relación medicina y salud pública, de hecho, per se, cualquier profesional de las ciencias de la salud que en su currículo ostente un componente de salud pública es sólo tan entendido en esa materia, así como lo es en cualquier otra que pueda haber cursado (microbiología, farmacología, bioquímica, ginecología, cirugía, etc.); es únicamente tan entendido en estos temas como los cursos básicos que pueda haber recibido de tales materias se lo permiten; Tampoco la práctica de la salud pública exige tanto como otras profesiones del área, apegarse a proporcionar ciertos servicios de acuerdo con un régimen establecido como lo hacen las especialidades médicas, más bien debe orientar sus intervenciones de acuerdo con el agregado social que enfrente, aunque con rigor académico-científico. Ciertamente, un médico y otros saben mucho de las materias que reciben; sin embargo, no es de esperar que sepan tanto como para lidiar con éxito con situaciones especiales o nuevas de cada una de esas áreas; por ejemplo, de la reforma en salud neoliberal preñada de falacias economicistas. Pongo especial interés en aclarar este punto por respeto a la susceptibilidad "a flor de piel" que en torno a estos temas prevalece.

Pero, además, las explicaciones proceden, porque esta confusión de conceptos ha sido aprovechada con mucha eficiencia por las fuerzas a favor de la reforma de salud neoliberal; por ejemplo, alrededor de 1993 se pusieron de moda los cursos para gerencia en salud sin "la contaminación" de ideas salubristas o de apoyo a lo social, a la par que se divulgó la noción de 
que lo privado es eficiente, sano y transparente, mientras lo público es todo lo contrario, cosa que la realidad se ha encargado de desvirtuar (en ambos ámbitos hay bondades y defectos) y que ya no vale la pena discutir. Así fue fácil vender la idea de que "expertos extranjeros" en reforma neoliberal podían "ungir" a expertos locales para privatizar y descentralizar, a la vez que las opiniones contrarias se desestimaban, todo lo cual pavimentó el camino para llegar a lo que es la norma en los países dependientes: que hasta en las universidades y otros centros de enseñanza superior se deslegitimen los abstractos y en cambio se legitimen las "lechitas", olvidando por supuesto que no hay "nada más práctico que una buena teoría" y que así como una teoría sin práctica es estéril, una práctica sin teoría es ciega, por lo que lo real y útil es su fusión lógica: la praxis.

Si nos negamos profundizar en el porqué de las cosas, nos negamos la independencia y el desarrollo; si nos lo negamos y lo dejamos en manos de los asesores extranjeros siempre seremos analfabetos y dependeremos de ellos. Si continuamos creyendo, a fuerza de marketing; por ejemplo, que la esencia de programas computacionales es compilar, "ponerse buzo" para elaborar largas cadenas de ceros y unos, sin preocuparnos por conocer a fondo el texto fuente que se compila, siempre seremos superfluos.

Como señalarán Thomas y Thiede en el 2005, dentro del proceso de globalización los poderosos imponen decisiones que favorecen sus intereses sobre los de otros; ellos ejercen su poder manteniendo ciertos temas fuera de agenda y perpetuando el status quo; o se las arreglan para moldear a su favor preferencias y creencias de los demás; es decir, que los poderosos ejercen el poder a través del conflicto directo, de evitar la discusión de ciertos temas y a través de la modificación de aquello en lo que se cree; o sea, previniendo el conflicto, cambiando la manera de pensar de los pueblos, cambiando sus ideas y valores.

\section{3. ¡Ave Caesar Imperator...!}

E n cuarto lugar, ya no se puede seguir ocultando tonterías y tal como nos explica Jon Sobrino (ECA No. 668, 2004), la palabra imperio, que parecía muerta, ha sido resucitada por la realidad y el imperio actual es los Estados Unidos; Sobrino también sostiene que hay que hablar de imperio para describir la postración en la que se encuentra el planeta, que no basta hablar de injusticia y de capitalismo para exponerla; que hay que hablar también del imperio, porque, entre otras cosas, "impone su voluntad sobre todo el planeta con un poder inmenso. Su mística es el triunfo sobre los demás con egoísmo cruel 
y a través de todos los ámbitos de realidad: economía, que no piensa en el oikos; industria armamentista, que no piensa en la vida; comercio con reglas inicuas, que no busca la equidad; destrucción de la naturaleza, que no piensa en la madre tierra; información manipulada y mentirosa, que no piensa en la verdad; guerra cruel, que no piensa ni en vivos ni en muertos; irrespeto al derecho internacional y a los derechos humanos...". Economía que supuestamente crece en todo sentido y lugar, menos en casa; y tampoco en los bolsillos de los menos pobres o de los presumidos, de los pobres y extremadamente pobres.

Sobrino reafirma lo que el Instituto de Investigaciones de las Naciones Unidas para el Desarrollo Social (UNRISD, por sus siglas en inglés), llamó estados de desorden: los efectos sociales de la globalización; fenómeno que John Kenneth Galbraith identifica como un invento de los estadounidenses para disimular su política de penetración económica en otros países y que UNRISD no vacila en identificar con diversos procesos que están conformados por fuerzas políticas poderosas, las que determinan quiénes se benefician (principalmente las transnacionales) y quiénes se perjudican (los pobres y los pauperizados del mundo, particularmente de los países subdesarrollados), ni vacila en identificar como la principal de esas fuerzas políticas al gobierno de los Estados Unidos. Reafirma, también contundentemente, lo que Chossudovsky documentó: la globalización es guerra, empobrecimiento y pobreza; y se nutre de las diferencias injustas entre países y dentro de los países.

Por supuesto, la historia es más complicada; pero, difícilmente se puede pasar por alto, tal como lo refiere UNRISD, que aproximadamente hasta la década de los años 80 del siglo pasado, después de la segunda guerra mundial, la economía de los países hegemónicos y a cuenta gotas la de los países dependientes, estuvo dominada por el keynesianismo que propiciaba la inversión pública con el fin de mantener el desempleo a niveles bajos y elevar los salarios reales; y por el fordismo, que propiciaba la producción masiva para mercados masivos, ya que el keynesianismo permitía que las empresas se prepararan para satisfacer una demanda creciente y sostenible, aprovechando un período especialmente propicio de reconstrucción de postguerra, así como de energía barata y ahorros, a su vez acumulados por la escasez de bienes domésticos. Aprovechando también nuevas tecnologías y nuevos productos de alta demanda, nuevos medios de transporte masivo (aviación), nuevas industrias (turismo masivo) y la guerra fría.

En esa época de oro del capitalismo, los países ricos, los Estados Unidos y la mayoría de países de la Organización de Cooperación y Desarrollo Económico (OCDE), siguieron los dictados capitalistas del estado de bienestar; y promovieron el pleno empleo y la protección y 
seguridad social para sus poblaciones y aún para las poblaciones de los países que volvían subdesarrollados al explotarlos; en las de esos mismos países a los que les venden la idea de que están en "vías de desarrollo" aunque no vean ese desarrollo o siquiera la vía. Esto lo hacían a pesar de que sus productos internos brutos (PIB) no crecían más allá del $4.0 \%$ anual ${ }^{2}$. Esta declaración es muy importante para contradecir a esos engreídos sin fundamento, que suelen señalar que sistemas de protección social únicos, públicos y universales, tales como los sistemas nacionales de salud de Inglaterra, Suecia, Canadá, etc., financiados por impuestos al ingreso y los de seguridad social de salud de Alemania, Francia, etc., financiados por impuestos a la planilla, sólo pueden darse con crecimientos económicos de 8 o $9 \%$ anual que permitan el rebalse propiciado por las "bondades" del libre mercado. Por supuesto, estas personas también tienen fuera de su mente el caso de Cuba, la antigua Unión Soviética, el antiguo sistema de China, etc.

Sin embargo, todo cambió con el alza de los precios del petróleo y de los cereales en los años 70, la recesión de los 80 y una serie de crisis fiscales subsiguientes, de manera que los Estados Unidos y el resto de países de la OCDE, restringieron sus estados de bienestar, desreglamentaron la economía para entrar al nuevo multilateralismo y la reestructuración global en la que juegan un papel preponderante el mismo gobierno de los Estados Unidos, sus creaciones de 1946 -el Banco Mundial, para "ayudar" a los países subdesarrollados y el Fondo Monetario Internacional (FMI), para "ayudar" a los países europeos devastados por la guerra- consejos privados de relaciones internacionales, agentes privados como el Grupo de los Treinta, que incluye grandes bancos y compañías de servicios financieros, y se apoya también en muchas empresas comerciales que operan más allá de las fronteras nacionales. La creación del BM y del FMI y el Acuerdo de Bretton Woods - para lograr tipos de cambio de divisas estables - producto de la Conferencia de Bretton Woods liderada por los Estados Unidos y Keynes, conforman junto con el GATT y el plan Marshall el "ramillete" de iniciativas políticas que le dieron un decidido empuje político y militar a la época de oro y a la guerra fría.

Es importante aclarar que en cuanto a la salud, el gobierno de los Estados Unidos, presionado por la Asociación de Médicos y Cirujanos de EE.UU., desde 1932 decidió no ofrecer cobertura médica universal a su población, sino que favoreció construir un sistema cuya columna vertebral es el seguro de salud apadrinado por el empleador, pero apuntalado por "un tratamiento respetuoso" en términos de impuestos federales y negociaciones relacionadas con la fuerza de trabajo, así como por Medicare y Medicaid. Según el economista Uwe Rein- 
hardt, ningún análisis de política sanitaria respaldaría este tipo de seguro financiado por el empleador $y$, de acuerdo con Romanow, en su totalidad, el sistema estadounidense termina siendo financiado en un $60 \%$ públicamente. De esta manera el sistema de salud de EUA es el mejor ejemplo de dinero público a plena disposición de la elite privada y sus "éxitos" se resumen en la aseveración publicada en el 2005, proveniente del senador Frist, hasta hace poco líder de la mayoría del senado: el estadounidense común sólo recibe aproximadamente 55\% de la atención de salud que paga por recibir y debe recibir, incluso cuando se trata de molestias y enfermedades comunes. Esto, a pesar de ser el sistema más caro del mundo. A muchos tal "atención" los deja en bancarrota y para más de 47 millones de estadounidenses menores de 65 años no hay seguro médico. Aún así, en el año 2000 la Asociación de Médicos y Cirujanos de EE.UU., que clama ser un vocero de los médicos privados de ese país, publicó que cuando Bismarck introdujo la medicina socializada en Alemania, había adoptado el socialismo nacionalista para terminar con el socialismo internacional, otra forma de decir que combatió el comunismo adoptando el comunismo. ¡Para ellos, incluso el mismo arquitecto del imperio alemán practicó el comunismo!

Probablemente, estas personas acuerpan declaraciones tales como la siguiente publicada antes en la revista NEJM: "ya no hay espacios para planes de salud sin fines de lucro en el nuevo medio de la atención de salud".

Por otra parte, en nuestros países el estado capitalista del bienestar a menudo se expresó, en cuanto a salud, en la triada compuesta por: un sector público, nacional, gratuito, pobre y basado en la consulta, que sería principalmente el recurso de los suficientemente pobres (caracterizado por la caridad, el paternalismo, las largas colas de espera, el "no hay", etc.) el cual, sin embargo, también subsidia a los demás componentes de tal triada; los seguros sociales (que en El Salvador ha llegado a cubrir al 16\% de la población, originalmente aquella que era la mano de obra calificada del proceso de "industrialización" de nuestros países dependientes) y el sector privado, a menudo también subsidiado por los seguros sociales y de muchas otras maneras entre las que destaca la gratuidad de la educación en las ciencias de la salud o su ridículo bajo precio y permisividad de iatrogenia. Aunque la norma de tales triadas ha sido el anuncio periódico de cambios y reformas que prometen mejoras, la realidad es que, tal como lo consignan Gwatkin y colaboradores, más bien todos los sistemas de salud resultan ser consistentemente inequitativos y proveen más servicios y de mejor calidad a quienes les va mejor en la sociedad y a quienes los necesitan menos, que a los pobres quienes lo necesitan más y están en 
menor posibilidad de obtenerlos. Bitrán reportó en el 2005 que en El Salvador existe un problema grave de acceso a la atención de salud para los pobres.

Para los países subdesarrollados, quienes habían adquirido grandes deudas para entonces, el punto clave fue la crisis del decenio de mil novecientos ochenta que los hizo sujetos de condicionamientos y ajustes estructurales neoliberales de sus economías, para que generaran un excedente destinado al pago de sus deudas, retiraran las normas a la actividad económica, privatizaran las empresas públicas y recortaran el gasto público, particularmente en los sectores tradicionalmente no sometidos a las leyes del mercado: Salud, educación, seguridad social y pensiones. Como el lector puede notar, desde entonces los sistemas nacionales de salud de nuestros países subdesarrollados están sometidos a restricciones de sus recursos.

Como consecuencia de esto las responsabilidades — no así los recursos- hasta entonces centralizadas, fueron descentralizadas hacia los gobiernos locales y a las comunidades; y además, se descentralizó lo privatizado con potencial de lucro. Privatización y descentralización son parte del plan neoliberal. Incluso algunos autores sostienen que la descentralización puede tener cuatro formas: desconcentración, delegación, devolución y privatización. Muchos sostienen que la descentralización tiene como fin la privatización en este contexto.
No hay que equivocarse. Es la crisis $^{4}$ del capitalismo la que impulsa la mundialización o globalización de carácter neoliberal y ésta impulsa la "modernización" del Estado cuyas expresiones operativas son reformas en diferentes áreas, una de las cuales es la del sector salud, la cual, además, es retomada directamente por el BM y sus aliados. Estas reformas bancomundialistas tienen dos finalidades que resaltan: privatizar y descentralizar. Entendiéndose desde el principio que privatización neoliberal es poner a disposición de la elite de la empresa privada toda la propiedad pública, en propiedad, arrendamiento, concesión o como más le convenga al grupo privilegiado.

Además, como parte del estado de desorden que implica la extensión de las fuerzas del mercado a escala global, muchas más personas han sido forzadas a emigrar en busca de una vida mejor del campo a la ciudad, y del campo y las ciudades a otros países, los cuales obtienen una fuerza de trabajo preparada para hacerse cargo de las tareas necesarias que la gente local no puede o se rehusa a llevar a cabo; tareas sucias, peligrosas y difíciles, relativamente mal remuneradas que condenan a los emigrantes a la pobreza en esas sociedades desarrolladas; y quienes, a través de las "remesas", terminan cerrando el círculo perverso en el que los pobres que migran y alcanzan una vida mejor, aunque siempre en pobreza relativa, en la mayoría de casos 
subsidian a los pobres y a los ricos ${ }^{5}$ de sus países de origen. Con la de que, tal como lo señala también UNRISD, el mismo trastorno social que obliga a la población a emigrar, probablemente también incrementa la criminalidad y favorece que la criminalidad esté adquiriendo una dimensión transnacional. ¡Cómo desearía poder decir que cualquier similitud con El Salvador, es pura coincidencia!

A la vez que las instituciones nacionales están siendo debilitadas y las comunidades y las familias se ven forzadas a aceptar nuevas cargas y responsabilidades (todos los servicios básicos suben de precio, los hospitales públicos cobran, los cuidados se descargan en las mujeres, los impuestos se recargan en las clases medias y populares, su desintegración, etc.) las empresas que operan a una escala global (transnacionales) gozan de grandes libertades sin que aumente su responsabilidad social en la medida correspondiente.

¿Será pura casualidad o tontería, acaso brillantez económica que supera a la de los maestros europeos, cuyos países, sin embargo, viven mejor que nosotros, la que explica que en este país los que tienen más ingresos paguen relativamente menos impuestos por el ingreso que los que tienen menos entradas? ¿Será este mismo tipo de razones el que explica que en este país habiendo un problema de delincuencia y de lesiones ligado principalmente a armas de fuego, no se hable de ningún impuesto a la importación, tenencia o portación de ellas, sino de imponer a la telefonía una carga para financiar el combate a la delincuencia? ¿No debería de ser primero a las armas y si no alcanza a otras cosas, que debería ir dirigido el gravamen?

Según el PNUD, la integración de los mercados comerciales, de inversión, financieros y de consumo, provoca la integración de la elite global y la marginación del resto de la gente y que muchos productos estén al alcance de sólo unos pocos, pero sean visibles para muchos.

Como consecuencia, ya en 1998 ¡las tres personas más ricas del mundo tenían activos superiores al PIB combinado de los 48 países menos adelantados! En el 2005 esta desmesurada obscenidad se agravaba.

En efecto, de acuerdo con el informe mundial sobre el desarrollo humano del 2005, el ingreso total de los quinientos individuos más ricos del mundo es superior al ingreso de los cuatrocientos dieciséis millones (416 millones) de los más pobres del mundo; se calcula que el monto para llevar a mil millones de personas a superar el umbral de pobreza extrema de un dólar al día es de $\$$ trescientos mil $(300,000)$ millones, cifra que representa únicamente el $1.6 \%$ del ingreso del decil más rico de la población mundial, quienes, dicho sea de paso, tienden a no pagar impuestos sobre la renta. Aún así, muchos engreídos sin fundamento defienden el postulado 
de no "sobrecargar" con impuestos a quienes no los pagan, para, según ellos, desacreditar propuestas de sistemas de salud únicos, universales y públicos financiados por impuestos a la renta de todos. Con tales ventajas, más propias de terrateniente abusivo de películas, que de empresario competitivo "hecho por sí mismo" como lo mercadea el neoliberalismo, quizá hasta esos engreídos "la harían" de empresarios.

El informe continúa diciendo que no se está cumpliendo la promesa hecha a los pobres del mundo; que las tendencias señalan que los objetivos de desarrollo del milenio no se van a cumplir (como ya lo hemos señalado en otros escritos) que lo primero es la asistencia para el desarrollo, pero que la asistencia actual se caracteriza por dos carencias: déficit crónico de financiamiento y mala calidad. Que primero es el desarrollo social como base para el desarrollo económico y que la inmensa pobreza y la obscena desigualdad son flagelos tan espantosos de esta época que deben clasificarse como males sociales tan graves como la esclavitud.

Pero esto no es casual, Hinkelammert, después de señalar que la globalización no es posible sin una acción constante y decidida de los estados, documenta que la ideología que la orienta y las acciones que ésta inspira, hacen que aparezcan muchos más capitales de los que sería posible invertir como capital productivo, y consecuentemente, una parte cada vez mayor de los capitales disponibles debe ser invertida especulativamente, pero debiendo realizar al menos la misma rentabilidad que la inversión productiva. Hinkelammert continúa explicando que tales posibilidades de inversiones especulativas se dan primero en aquellos sectores de la sociedad que se han desarrollado fuera del ámbito de los criterios de rentabilidad: actividades sociales del Estado transformadas en esferas de realización del capital. Pronto seguidas, sin embargo, por cualquier otra actividad humana. De acuerdo con él esto explica la presión mundial hacia la privatización. La presunta dignificación de la prostitución con el apelativo de "trabajo de sexo" tiene también el propósito de facilitar la conversión del acto sexual de este tipo en esfera de realización del capital especulativo.

No sólo Hinkelammert hace esta clase de señalamientos; James D. Wolfensohn, presidente del grupo del Banco Mundial, reconoció en 1998 que dado que con demasiada frecuencia las acciones del BM se habían centrado excesivamente en lo económico sin comprender bien los aspectos sociales, políticos, ambientales y culturales de la sociedad, era necesario ir más allá de la estabilización financiera y pensar en la prosperidad y el progreso humano, así como ocuparse de los problemas sociales. Por supuesto, esto después de que el Banco Mundial publicara su informe anual de 1993, Invertir en salud, que sentó las bases de todas aquellas injustas 
acciones de salud centradas excesivamente en lo económico. En este caso, lo importante es saber separar las lágrimas del cocodrilo.

Mientras tanto, en nuestro medio muchos "entendidos", "amigos de ANSAL" y reformistas se mantenían y mantienen negando la privatización y la descentralización evidentes, alegando que sólo se está contratando, delegando, devolviendo, descongestionando, etc., recurriendo a la "viveza del ratón" de que como en el Estado hay tantas funciones de atención médica y de salud pública y de otro tipo que pueden ser ejecutadas por tanta clase de organizaciones privadas que pueden existir, al cruzar estos dos grupos de factores es posible encontrar literalmente cientos de sinónimos con los que se puede encubrir la privatización y de una manera similar la descentralización. Increíblemente, entre ellos destacan miembros de los últimos cuatro gobiernos centrales, furibundos y supuestamente inclaudicables paladines del nacionalismo, quienes no vacilan en pedir la sangre de cualquiera que a su criterio atente contra la patria y que celebran la muerte de quienes se les oponen $y_{\text {, }}$ curiosamente, también aborrecen a presidentes salvadoreños que besan la bandera de Estados Unidos, aunque, contradictoriamente, aplauden a otro presidente que, ostentando ese cargo, declaró que el más grande honor de su vida es que el presidente Bush lo tenga como amigo. ¿Pero qué hacen realmente nuestros ilustres nacionalistas de acuerdo con los hechos expuestos y el orden de cosas revelado en los párrafos anteriores? Pues primero, venden la patria, segundo, venden la patria cada vez que niegan lo innegable; tercero, también venden la patria y despojan de sus derechos a los verdaderos patriotas. $i A$ quién se la venden? Pues a las transnacionales, y a los gobiernos de la OCDE. Por supuesto, no son los únicos que la venden, también lo hacen aquellos que creen o dicen creer que no hay que ser tan "cavernícolas" y que un poquito de privatización o descentralización no hace daño, y aquellos a quienes se les olvida que esta globalización no respeta ni a los capitales locales (La Constancia, el Banco de Comercio, el Banco Cuscatlán, el Banco Agrícola Comercial, etc., son nuestros testigos) y tiende a separar a los que tienen de los que no tienen o apenas tienen.

¿Y quiénes son los más vulnerables? ¡Los pobres pero presumidos y por supuesto, los pobres! Pobres en todos esos casos y presumidos en algunos, porque en El Salvador el ingreso promedio del más alto decil de ingresos es menor que el ingreso que marca la línea de pobreza en los Estados Unidos, pero algunos salvadoreños lo ostentan como si ese ingreso fuese el triple; porque, ¿cuántos salvadoreños estaban o pudieron estar con solvencia, estilo y honradez en las listas de espera de bolsos de mano de cuatro mil dólares, relojes de cuarenta y cuatro mil o carros de setenta y cinco 
mil dólares que se produjeron en la época de oro de la economía del mercado? Porque en El Salvador un ingreso mensual de tres mil quinientos dólares (obtenido honradamente, por supuesto pasando por alto las iniquidades de base y la perversidad de la acumulación original de capitales que lo permiten) es extremadamente raro y deseado; pero, es sólo un poco mayor que el sueldo que se le ofrece a un profesor universitario recién graduado en Estados Unidos. Y, no hay que olvidar que en El Salvador estamos dolarizados, que el salario mínimo diario, recientemente reevaluado, es de \$5.81 en este país, sólo un poco mayor que el salario mínimo por hora (\$5.15) en EUA, el cual, el Partido Demócrata quiere elevar a \$7.25 la hora; tampoco debemos olvidar que, de acuerdo con la CEPAL (2006), el salario medio real se redujo en El Salvador durante el trienio 2003-2005.

\section{4. ¿Neoliberalismo científico o imperial?}

C onsecuentemente, en quinto lugar, ya no se puede seguir ocultando que la propuesta neoliberal no tiene fundamento científico, que ella y la globalización descansan en opiniones y supuestos de fuerzas políticas imperiales; que la gran ofensiva privatizadora del sector salud está fundamentada en una concepción individualista que si tiene algún fundamento es ideológico, puesto que no hay ni un éxito empírico ni evidencia científica, que sustenten esa idea. De hecho, el proceso salud-enfermedad sólo tiene una dimensión real, la colectiva; lo que se considera un caso de salud o enfermedad individual es sólo una expresión episódica carente de autonomía, del proceso colectivo.

Por supuesto, todo esto tiene relación con los atributos del capitalismo, particularmente con la motivación hacia la acumulación que proporciona a las economías capitalistas la energía que las caracteriza y que se expresa en la búsqueda incesante de nuevas tecnologías y mercados. Pero también se relaciona con el hecho - casi una ironía también- de la incapacidad que tiene el capitalismo de encontrar continuamente, de manera indefinida, nuevas áreas productivas para la inversión. Todo esto también se relaciona con que el capitalismo se caracteriza por encubrir su carácter explotador bajo las relaciones salariales, y con que ya haya finalizado la era de oro del capitalismo, con el surgimiento de la cuarta globalización del capital, del neoliberalismo y del concomitante individualismo posesivo que artificialmente eleva la propiedad privada al nivel de característica esencial de la naturaleza humana y que sostiene que el ser humano es 
libre y que esta libertad reside en el hecho de que cada individuo es propietario de sí y sus bienes y se constituye en la raíz del valor libre elección del neoliberalismo.

Cabe agregar, que el capitalismo crea sociedades que no hacen suya la responsabilidad por la manutención de la persona que debe vender su trabajo y en las cuales el comprador de la misma no se siente responsable de que el salario sea suficiente para que el trabajador subsista. Es evidente que el capitalismo ni siquiera intenta ser solidario o equitativo. En esto participa decisivamente el mercado -otro atributo distintivo del capitalismo- el supuesto coordinador equitativo e invisible de la producción y la distribución en dicho sistema, porque en realidad facilita obviar enseñanzas morales de aplicación cotidiana y hacer a otros lo que no desearía para uno; porque los mercados son económicamente efectivos pero moralmente recursos dudosos para guiar el comportamiento económico.

También participa en ello el atributo olvidado del capitalismo: la división del poder y la autoridad entre un sector público y otro privado que supuestamente deben funcionar eficiente y coordinadamente así como con fines inteligentes, o sea persiguiendo el bienestar colectivo. Según Heilbroner y Milberg, lo importante es la paridad del interés público con el privado, salvo en casos especiales - guerras y otras emergencias-cuando el sector público debe prevalecer. Por supuesto, esto descubre la perversidad de la pretensión neoliberal de poner al patrimonio público al servicio incondicional de la elite del sector privado.

La argumentación anterior facilita una sexta aseveración. Está perfectamente documentado que el capitalista Banco Mundial propuso tan temprano como en 1987 disminuir la responsabilidad del gobierno en el financiamiento de intervenciones sanitarias sin externalidades, con lo cual, según el BM, la atención curativa queda excluida ${ }^{6}$, excepto la atención a los paupérrimos; y consecuentemente, propuso cuatro políticas financieras de los sistemas de salud: cobrar por servicios curativos, ampliar el seguro obligatorio a los trabajadores del sector formal; incentivar al sector privado a ofrecer aquellos servicios curativos que la población está dispuesta a pagar; y descentralizar los establecimientos públicos cuyos servicios pueden ser cobrados a los usuarios en especial los hospitales. Además, el BM presiona a los gobiernos para que se desatiendan de la salud, excepto cuando el sector privado no puede o no quiere prestar el servicio, lo cual reafirma que el objetivo principal de la política neoliberal es aumentar el papel del sector privado en los asuntos públicos como un medio para revalorizar el capital y aumentar su rentabilidad. 


\section{La validez de la propuesta de enfoque mixto}

E sto nos conduce a una séptima aseveración. Si lo que se persigue es construir un sistema de salud eficaz, eficiente, solidario y equitativo, no hay espacio para el mercado o para el enfoque mixto, ni para cualquier otro elemento que favorezca la penetración del sector privado con fines de lucro en el sistema público, puesto que dicho sector orienta sus actividades a las áreas más rentables y procura florecer en los asentamientos urbanos y entre los más ricos, y además, porque está plenamente demostrado que en materia de salud los mercados también son ineficientes.

Pero, ¿no será ideológico, o simple idiotez, rechazar hasta el financiamiento privado de los sistemas precariamente financiados con dinero público? Al menos, los estudios de Tuohy y sus colaboradores, efectuados en 2004, indican que este tipo de mixtura tiene más probabilidades de dañar, puesto que tiende a drenar recursos del sistema público.

Además, varios estudios han podido constatar que hay tres problemas serios que pueden surgir de las mezclas público-privadas, aún cuando sólo impliquen financiamiento de parte del sector privado: la calidad disminuida de los servicios prestados; paga, términos de contratación y condiciones de trabajo problemáticas para los traba- jadores; tiempo de pago retardado por parte del sector público que puede llevar a su endeudamiento a largo plazo y que puede neutralizar cualquier incentivo para que el sector privado sea eficiente.

El sector privado no ha podido controlar su afán de lucro, por eso, en lugar de contribuir a la eficiencia, tiende a crear problemas de equidad y costos virtualmente incontrolables. Hay cantidad de evidencia a favor de que la lógica del servicio privado de salud está orientada, casi de forma exclusiva, a lo curativo-paliativo $y$, en consecuencia, abusa de la dimensión tecnológica de los servicios y de la hospitalización. Su criterio es la rentabilidad y la comodidad profesional, lo cual hace que a menudo aplique procesos claramente iatrogénicos. Luego pasa a la "iatrogénica económica". La búsqueda de rentabilidad cierra el espacio al servicio gratuito o al costo. Así, mientras el sistema público se beneficia de la ausencia de enfermos, el privado con fines de lucro necesita de ellos, siempre que puedan pagar. Ahí donde se ha dado participación al sector privado, a través de concesiones, subrogaciones, pagos estatales directos o seguros privados o pagados por el Estado, se han elevado el costo, la desigualdad, el fraude, la corrupción y la explotación del trabajo profesional. 
La supuesta eficiencia de sistemas mixtos o privados con financiamiento público se fundamenta mucho en el ahorro que se hace a expensas del personal de salud, sobre el cual recae una creciente carga laboral y un recorte de salarios y prestaciones, a través de la liberalización de los contratos; y también se produce a costa del usuario quien debe hacer erogaciones a todos los niveles.

Pero, Latinoamérica es todavía más vulnerable a estas mixturas. Se estima que nueve millones de personas trabajan en el área de salud de América Latina y puesto que este sector dedica casi el 70\% de sus recursos al pago de salario, el uso intensivo de la mano de obra es crítico para incrementar la eficiencia, la productividad y la calidad de los servicios; sin embargo, esto se ve obstaculizado por: el carácter flexneriano de la educación básica en ciencias de la salud, la desproporción entre las diferentes categorías de profesionales y técnicos; la desproporción entre el número de profesionales de centros urbanos y rurales; el pluriempleo médico; la falta de control gerencial de los recursos humanos; por baja capacidad gerencial; débil regulación de la práctica profesional y la deficiente comunicación entre los proveedores de salud y los usuarios. Además, el empuje neoliberal ha auspiciado: entrenamiento gerencial que en general no mejora la capacidad gerencial; el programa Flagship de promoción de la reforma neoliberal entre los altos ejecutivos de la re- gión; adiestramiento en la preparación y administración de contratos para facilitar el cumplimiento de la exigencia neoliberal acerca de una mano de obra flexible que permita despedir a un empleado cuando el empleador lo considere necesario, particularmente para reducir los costos e incrementar la eficiencia; sobre la base ideológica neoliberal de que el temor de los trabajadores a perder su empleo aumenta la productividad y mejora la calidad ¿ No es esto terrorismo laboral?

En realidad, la supuesta evidencia a favor de los servicios cumplidos privadamente con afán de lucro deriva de resultados en situaciones en las cuales las empresas privadas pueden "descremar" los servicios que, fácil y económicamente, pueden ser cumplidos con base en el volumen, mientras el servicio público carga con los servicios más caros y complicados, cuyo costo debe ser calculado caso por caso, y carga además con los costos irrecuperables del apoyo que le da al servicio privado, cuando éste comete errores que exigen el tratamiento intensivo de las personas y que él no puede cumplir porque no le son rentables. La evidencia proveniente de Estados Unidos sugiere que la calidad de atención del sector que opera sin afán de lucro es mejor que la calidad de la atención privada ofrecida, por ejemplo, por HMO y hospitales que operan por lucro. Los hospitales que operan por lucro han mostrado un incremento en el riesgo de morir, en relación con la contraparte 
que opera sin afán de lucro, quizá porque tienden a emplear personal menos capacitado. Además, los servicios contratados con compañías privadas permiten la compra de servicios públicos que de esa manera sí son cumplidos más prontamente, aunque también se propicie que los recursos económicos individuales determinen el acceso, a menudo desordenado a los servicios públicos; cabiendo siempre la duda sobre si dichas compras obedecen a una razón económica legítima o a una perversa; por ejemplo, a favorecer "maquiladores" o a comparar lo público con lo privado en condiciones favorables a lo privado o a una combinación de estas razones.

Otros trabajos también permiten concluir que los hospitales con fines de lucro de los Estados Unidos son menos eficientes que las organizaciones privadas sin finalidad lucrativa y que los hospitales públicos; y que si acaso obtienen resultados comparables es con un costo mayor.

Pero si de lo que se trata es de obtener un servicio de salud eficaz, eficiente, solidario y equitativo que mejore la salud de la población, tampoco caben propuestas de mixturas "pluralistas-estructuradas" como la del Londoño y Frenk o público-autónomas, estas últimas usualmente producto reactivo, bien intencionado pero erróneo, de intelectuales más bien de izquierda insuficientemente informados o que intentan proteger intereses tradicionales de izquierda sin quedar como "dinosaurios", pero que de todos modos terminan quedando como "razonables" ante el BM y compañía, y consecuentemente, haciendo el juego al neoliberalismo. Este tipo de mezcla también se puede usar con clara intención privatizadora, así lo hizo ANSAL en 1993-1994.

La mezcla público-autónoma (que en nuestro medio tomaría la forma de MSPAS-FOSALUD y todas, algunas o alguna de las siguientes instituciones: ISSS, Bienestar Magisterial, Sanidad Militar y Consejos Superior de Salud Pública) no es viable ni siquiera desde el punto de vista de asesores del BM y Compañía.

En efecto, Bitrán señaló en el 2005, que la integración del MSPAS con el ISSS no es ni equitativa ni políticamente viable, sobre todo en la versión en las que los proveedores de ambas entidades pasan a constituir una misma red, y el financiamiento de ambas se junta para luego ser redistribuido en partes iguales por beneficiarios.

Además, obviamente si la mezcla involucra al ISSS, ésta se vuelve público-autónoma-privada, debido al financiamiento tripartito de la institución (gobierno, empleadores y trabajadores). Sin embargo, también el financiamiento sería inequitativo y poco práctico, puesto que implicaría IVA, impuestos a la planilla, a la renta y desembolsos directos del bolsillo ${ }^{7}$, así como engorroso y por ello mismo implicaría una administración más costosa. Como no es 
probable que el MSPAS-FOSALUD aumente el per cápita $(\$ 50)$ y dado que debe cubrir a cerca del $84 \%$ de la población (de hecho toda la población tiene derecho) y puesto que el ISSS tiene un per cápita de 223 dólares para cubrir al 16\% de la población aproximadamente, la equidad en la disponibilidad de dinero para la atención sólo podría ir a la baja en defecto del cotizante del ISSS de acuerdo con las cifras y con la lógica usual de los proponentes de este tipo de mixturas, la cual usualmente recomienda dividir "equitativamente" los aportes totales entre el número de personas cubiertas.

Sin embargo, esta lógica "salomónica a la salvadoreña" ${ }^{8}$ no sólo no es equitativa, sino que también pasa por alto que el ISSS y en general los Institutos Latinoamericanos de Seguridad Social, cubren sólo lo que pueden cubrir: los servicios necesarios para el alivio, la cura y la rehabilitación de la mano de obra especializada de los países, servicios que son además, los menos frecuentes y los más caros, puesto que la tan baja proporción de población empleada en el sector formal de la economía ha sido un factor decisivo para que los institutos latinoamericanos de seguridad social no puedan alcanzar los niveles de dilución de riesgo requeridos para servir de base adecuada para todo un sistema nacional de seguro de salud como existe en Alemania, Francia, Holanda, Costa Rica, etc., es decir, la simple fusión-dilución desvía al
ISSS de su propósito original, lo pervierte, así como al propósito del sistema fusionado público-autonómas propuesto.

¿Exageración? Supongamos que no hay ni corrupción mayor (robo, mal manejo o desvío de fondos, sabotaje neoliberal o intención privatizadora, etc., aunque se piensa que en El Salvador cada vez que algún valor se mueve del lugar hay lugar a "movida"), ni corrupción menor (ausencias, raterismo, desperdicio, desconsideración, etc.) y asumamos también la fusión óptima de gestión bajo la rectoría del MSPAS y además asumamos solidaridad entre el derechohabiente actual del ISSS a quien se le descuenta de la planilla y aquél que "no paga" pues no se le descuenta de la planilla ¿Cómo podría entonces el rector de esa mixtura mejorar la salud de toda la población salvadoreña y mantener fuerte a la mano de obra con 78 dólares per cápita aproximadamente, sino a podido hacerlo con menos del $40 \%$ de esa población disponiendo de 50 dólares por persona del $84 \%$ de la población? ¿Mediante qué artificio podría, en estas circunstancias, transformar al ISSS en una institución de atención especial en una que también cubra eficaz y eficientemente servicios comunes, frecuentes y esperados? ¡Sólo con un milagro! Es decir, en realidad no podría.

Expliquémonos mejor. En el presente, las propuestas de aseguramiento social de la salud pueden resumirse en programas nacionales 
que procuran financiar ciertos servicios de salud con impuestos a la planilla (a los salarios) y que usualmente implican la creación de una entidad autónoma para manejar los fondos separando el financiamiento de la atención y de su provisión y reforzando el financiamiento con contribuciones de los empleadores y del Estado. Aunque la intención de usar los seguros sociales como fundamento de los sistemas de salud sea compartir la carga del costo de la atención de salud entre los hogares por asegurar, es obvio que, en este papel, el seguro social deberá intentar cubrir servicios de salud comunes, frecuentes y esperados, los cuales, por estas mismas razones constituyen riesgos "no asegurables" y cubrirlos eficientemente implicaría primas que son muy altas en relación con los beneficios.

Este tipo de seguros sociales puede cubrir aquellos servicios que son menos frecuentes aunque más costosos como puede ser ilustrado por un ejemplo extraído de la práctica de salud dental. En efecto, un chequeo anual es considerado costo-efectivo y recomendable para todas las personas, sin embargo, desde el punto de vista del costo para un sistema de seguro social con una difusión de riesgo limitada, la prima de asegurar esa medida preventiva debería costar al menos lo que vale una visita al dentista por miembro asegurado, mientras que sólo se necesitaría un cargo pequeño adicional para cubrir servicios que aunque sean muy costosos son menos frecuentes: tratamientos de canal, implantes, etc., que son los que conforman la porción de los costos diluibles. Consecuentemente, es difícil usar la eficiencia de diluir el riesgo para subsidiar la atención de los pobres por medio del seguro social y más bien la introducción de un nuevo fondo de seguro puede desviar la atención del debate social que sí cuenta; es decir, el de cómo hacer que las personas más adineradas paguen impuestos para subsidiar la atención de los pobres.

La separación entre el financiamiento y la provisión también representa uno de los grandes riesgos en aseguramiento social cuando los que financian son pasivos, los proveedores pueden hacer efectivos incrementos injustificados de costos e inflar el gasto en salud; de hecho, los pagos para el seguro social pueden no desplazar al pago directo del bolsillo, en cuyo caso, los hogares, que son los que terminan pagando las cuentas de salud, pueden terminar con una cuenta más alta que antes. De hecho, en las circunstancias actuales de los países subdesarrollados un seguro social de este estilo difícilmente puede dar la atención debida a los asegurados sin el apoyo de los servicios públicos.

Se ha planteado que en los países subdesarrollados de bajos ingresos la introducción del seguro social es probablemente una mala idea puesto que el problema de esos países no es de financiamiento ineficiente, sino de gobernabilidad 
política que regularmente financia inadecuadamente a los servicios de atención de salud y gasta los fondos públicos ineficientemente. No se puede menospreciar el riesgo para la mayor parte de países subdesarrollados en relación con los sistemas de seguros sociales, de que los problemas políticos fundamentales de gobernancia de los sistemas de salud no van a cambiar con la introducción de seguros sociales o con las reformas de ellos, sino que más bien serán exacerbados.

Se dice que las mezclas público-autonómas obedecen al deseo de proteger a los sindicatos; sin embargo, no veo porque éstos no podrían operar en un sistema como el que propondremos. Me imagino que algunas creencias con las que se ha apuntalado la idea de favorecer coberturas universales de salud basándose en institutos de seguro social, también respaldan a las mixturas público-autonómas aunque también sin mucho fundamento. Por ejemplo, aunque los impuestos o los descuentos al salario se consideran más fáciles de recolectar que los impuestos generales o las primas voluntarias y se cree que les dan a los trabajadores una posición de poder dentro del sistema de seguro, además de que obligan a los empleadores a contribuir en el costo de atención de salud de los trabajadores y también a pesar de que se cree que son más estables que las partidas derivadas del presupuesto general, la verdad es que la facilidad de recolección se limita al impuesto a aquellos que trabajan en el sector formal y en la mayor parte de países subdesarrollado ese sector es muy pequeño y va en la vía de empequeñecerse más, de manera que este sistema de seguro tiene todo para convertirse en un privilegio. También es verdad que sostener que la contribución de los empleadores reduce la carga de los trabajadores es un argumento un poco inocente, pues ignora el hecho de que estas contribuciones vienen de las ganancias que dejan los negocios y que consecuentemente son pagadas en mucho por los consumidores —incluidos los trabajadores - en la forma de altos precios y por los trabajadores en la forma de bajos salarios, y tampoco los impuestos al salario son más estables que las partidas presupuestarias.

Sin embargo, lo expuesto en los párrafos precedentes no debe ser defensa de burócratas incapaces y abusivos, en mucho productos del clientelismo político omnipresente; tampoco para ciertas actividades reivindicativas laborales o simplemente salariales sin respeto al patrón ético vigente: una huelga en el campo de la salud sólo podría ser lícita si defendiera derechos y sólo como último recurso y con ciertas condiciones —una violación previa de los derechos básicos, un daño mayor para la salud, previsible y demostrable, que el que ocasionaría la huelga y seguridad plena de que ella no causará daño grave a los enfermos- pudiéndose completar 
dicho patrón con la necesidad de un acuerdo entre potenciales huelguistas y pacientes en pro del bien común. Fuera del patrón señalado, la huelga no es ética, porque no persigue el bien común, hace sufrir al enfermo y lo arriesga a grave daño e incluso a morir por el hecho de no atenderlo y porque le impone renunciar a un derecho y la conformidad a sufrir, con el pretexto de que es por su bien o sobre la base de que para "curarse debe ingerir antes una medicina amarga", como solía señalar otro ex presidente de El Salvador. Este grupo de aseveraciones constituye nuestra octava premisa.

\section{El sistema de salud que merece la población salvadoreña}

$\mathrm{E}$ sto conduce a nuestra novena aseveración: que necesitamos, como sociedad, un sistema de salud único ${ }^{9}$, de carácter público, igualitario, solidario, modernamente universal (que no ofrezca todo a todos, sino que establezca prioridades); proactivo, que busque la problemática, que busque dar la atención y no confíe tanto en la consulta; de naturaleza pública, con enfoque público y centrado en resultados finales; y regulador de un sistema privado cuyos espacios pueden ser fundamentalmente diferentes de los del sistema público.

Para ser equitativo y solidario, así como nacional, universal, pagado con antelación y permanente, deberá, tanto ser financiado, al menos de manera principal, por impuestos al ingreso, como retomar que el acceso a los medicamentos básicos es un derecho humano fundamental y que una situación similar se da para otros insumos críticos; también deberá reconocer la necesidad de cambios estructurales para su viabilidad y proceder a concretarlos como parte integral del sistema que realmente son.

El sistema de salud que merece nuestra población es uno que rescate la salud pública y que dentro de él se le reconozca a esta ciencia el carácter principal en relación con la atención médica que la misma investigación biomédica le ha otorgado en el proceso de alcanzar el nivel de salud deseado por todos o de evitar muertes prematuras. En efecto, algunas mediciones indican que la atención médica, la cual puede absorber más del $90 \%$ del gasto nacional de salud, incide sólo entre un 10 y $11 \%$ en el nivel de salud, mientras los factores asociados a la salud pública (medio ambiente y el llamado estilo de vida) contribuyen entre un 62 y un $70 \%$ y consumen tan poco como el 3\% o menos de los recursos. Lo que nos merecemos es un sistema que primero minimice los riesgos a la salud del público y si estas previsiones fallan y las personas enferman, las atienda debidamente. 
La equidad vertical del financiamiento equivale a su progresividad, es decir, equivale a cuanto la fuente de financiación favorece que los más pobres contribuyan menos en comparación con su renta y los más ricos relativamente más.

La fuente de financiación más progresiva es el impuesto sobre la renta o ingreso; mientras el IVA, los seguros privados de salud y el pago directo del bolsillo son fuentes regresivas de financiación. De hecho, ni el porcentaje de IVA o el precio de un seguro privado, ni las cuentas por atención médica se reducen frente a la pobreza. Además, todo dinero que nutre financieramente a los sistemas de salud proviene de la productividad local y de los hogares.

Garantizar la provisión y el acceso a medicamentos y otros insumos críticos e incluso evaluar la conveniencia de adoptar la estrategia de la producción local ${ }^{10} \sin$ ánimo de lucro y bajo control estatal de estos bienes esenciales es imperativo, tanto porque ningún sistema de salud del mundo es capaz de resistir la actual escalada de precios de los medicamentos abusiva y descontrolada ${ }^{11}$, como porque tal escalada no es ni racional ni justa, sino la expresión de las políticas de acumulación dañinas - $\mathrm{O}$ al menos inseguras- de Big Pharma, el consentido "club" de las transnacionales farmacéuticas; y consecuentemente, también es necesario retomar esta idea en atención a que, tal como lo plantea De Paola, ser civilizado es lo opuesto a aceptar la perversidad y la injusticia como virtudes.

La construcción de este seguro de salud pública pagado con antelación deberá partir del sistema actual, pero para transformarlo mediante el esfuerzo fundamentalmente ético de mejorar la salud de la población equitativamente. Para lograr todo lo anterior sus constructores deberán también superar la difundida tontería de que en El Salvador impera un perfil epidemiológico de país subdesarrollado y que sólo o principalmente ${ }^{12}$ enfermamos y morimos de IRAS, diarreas, avitaminosis, etc., porque esa tontería es un concepto erróneo y porque, no obstante, los proponentes de la reforma neoliberal lo aprovechan para "justificar" que como parte de su reforma ofrezcan gratuitamente sólo paquetes básicos de salud y únicamente para los indigentes. No, el perfil epidemiológico de El Salvador así como de otros países abusados, es más bien de quíntuple carga: enfermedades infecciosas endémicas y epidémicas de masas, emergentes y reemergentes; enfermedades no infecciosas en vertiginoso ascenso; una epidemia de violencia y lesiones; otra de enfermedad mental muy ligada al alcoholismo y a otras adicciones; todo ello en un marco de hambre y de pobreza, así como de deficiencia nutricional silenciosa y silenciada, coexistente con sobrepeso y obesidad.

Es evidente que sólo considerar el primer nivel de atención de salud necesaria para afrontar el perfil real 
revela lo ridículo y, o perverso de la propuesta de paquetes básicos de salud muchas veces reducido a sales de rehidratación oral, algunas vacunas y quizá a una que otra "toma" de vitamina A o de ácido fólico.

La décima premisa que incluiré en este escrito, consiste en que ahora, quizá más que nunca, es cuando los dictados éticos, que en el área médico-sanitaria equiparan lo injusto con lo erróneo, pueden hacer la diferencia, porque, entre otras cosas, el avance del mercado inmoral como referencia de conducta económica apropiada propicia la anulación teórica y práctica de tales dictados; por ejemplo, si bien es cierto que la conversión de la atención médica o de salud pública en una mercancía no es invento ni del BM ni de la reforma neoliberal; que, por el contrario, ésta comenzó con la decisión de los profesionales de las ciencias de la salud de tratar de vivir fundamental o exclusivamente de los ingresos provenientes del cobro por sus servicios de atención, también es cierto que a pesar de que tal práctica se acentuó a partir de 1800 por iniciativa de la Asociación Médica de los Estados Unidos, ésta estaba regulada por un código de ética que las más de las veces funcionaba, sobre todo en la relación médico-paciente; así como es un hecho que todo cambió drásticamente a partir de la intromisión directa del BM y del interés economicista en el campo de la salud en 1993, cuando la atención de salud se consideró sólo otra mercancía, tan sujeta a las leyes del mercado y tan libre de códigos de ética salutogénicos como cualquier otra mercadería en venta.

En onceavo lugar, listaré un cúmulo de abusos contra la salud pública cometidos por verdaderos "delincuentes terroristas" con la ayuda material o al menos el apoyo de muchos ignorantes engreídos que circulan en el ámbito de las ciencias de la salud.

Esta declaración es necesaria pese a su claro carácter controversial y su dureza ¿Cómo podría no serlo? Cómo, sobre todo en un país en donde la expulsión de ciudadanos hacia EE.UU., debida fundamentalmente al subdesarrollo empobrecedor provocado justamente por ese mismo país, es llamada "sueño"; cómo, si cuando esa nación centro del imperio - conformado originalmente por inmigrantes culpables de latrocinio con los indígenas - erige un ignominioso muro y permite que sus propios ciudadanos sean cazadores de "ilegales", para que los "cafecitos" habitantes de su "patio trasero" ya no podamos migrar y realizar los "soñados" trabajos indeseables para su población, oficialmente casi se aplaude "ese gesto" de algunos norteamericanos y virtualmente sólo falta agradecer con toda pompa su desprecio y la discriminación a la que nos someten, pretextando que EE.UU. está en su derecho y que así el buen vecino impide que tantos "coyotes", casi terroristas, abusen de nosotros en el camino a la libertad... 
os abusos o tropelías a los que me refiero son: la primera, que es un hecho que el pasado reciente y el presente de la mayor parte del mundo son de colonialismo y neocolonialismo y El Salvador y Latinoamérica no han sido ni son la excepción. Y esto, evidentemente, constituye una tropelía fundamental contra la salud mundial.

Por supuesto, la imposición de la medicina tropical (investigación científica) en detrimento de la salud tropical (salud del público) para el "desarrollo" de los países colonizados es una segunda tropelía a la salud pública que, para agravar las cosas, no es separable de otra tropelía que se gestó aproximadamente al mismo tiempo. Esta tercera tropelía consiste en la combinación del Ilamado cisma medicina-salud pública con la "flexnerización" de las escuelas de medicina, la cual se produjo principalmente en los Estados Unidos y en Canadá; pero, como los estornudos de países centrales resultan a menudo en catarros o gripes de países periféricos, repercutió en muchas partes del mundo.

El cisma que claramente disminuye los potenciales científicos y virtualmente los de todo tipo de ambas ciencias, es, por ello mismo, un absurdo, aunque, por otra parte, la práctica de la medicina y la salud pública deba respetar aquello de "zapatero, a tus zapatos".
Sin embargo, la escisión fue un acto deliberado, pese a que las bondades del ejercicio conjunto eran evidentes, ya que, entre otras cosas, muchos clínicos y profesores de medicina percibían como parte de su quehacer profesional actividades tales como diseñar y aplicar medidas destinadas a mejorar la salud pública aplicando conceptos y métodos epidemiológicos y estadísticos, tanto que muchas de las nociones fundamentales para dar respuesta a los problemas de salud pública fueron generadas por médicos en ese tiempo anterior al cisma. Fue con el advenimiento de la teoría germen-enfermedad que el estamento médico se volcó hacia la descripción de microorganismos y la investigación en el laboratorio de bacteriología y comenzó a descuidar los estudios sobre las características del hospedero y del medio ambiente y los estudios epidemiológicos en poblaciones, los cuales además se centraron en investigaciones sobre enfermedades infecciosas. La epidemiología se hizo casi sinónimo con bacteriología, y la bacteriología con biomedicina; pasar de ello al dominio del monocausalismo centrado en los microorganismos y partículas infecciosas fue sólo cuestión de tiempo.

Lo que contribuyó más al cisma fue la decisión que tomaron los ejecutivos de la fundación Rockefeller 
en 1916 de apoyar la creación de escuelas de salud pública separadas de las escuelas de medicina, lo que, entre otras cosas, imprimió un impulso adicional al desarrollo de ideas que separaban el abordaje individual del abordaje demográfico a los problemas de salud-enfermedad.

Una de las primeras víctimas de tal decisión fue el enfoque epidemiológico legítimo que tiene a la comparación como estrategia fundamental. Y es que después de todo la comparación provee los fundamentos usuales para "redefinir lo inaceptable", puesto que se concluye que determinada situación es inaceptable cuando se le contrasta con algo que ocurrió antes, con algo que puede ocurrir o con otras situaciones que se están dando en algún otro lugar.

La teoría del germen-enfermedad ayudó a desviar la atención de la naturaleza fundamentalmente explotadora de la sociedad comercial capitalista y facilitó "culpar a la víctima" al quitarle a la sociedad la responsabilidad por la enfermedad y ponerla en los gérmenes en una primera instancia, para luego atribuírsela a las personas, sobre todo a los pobres, con base en su ignorancia y su forma antihigiénica de vivir, de manera que eventualmente la enfermedad fue aceptada como responsabilidad del individuo y la atención individual de salud basada en hospitales y en la consulta intramuros como la norma de atención.
Los ejecutivos de la fundación plantearon que la solución estaba en establecer escuelas de salud pública que fueran responsables por estudiar las determinantes de la salud y la enfermedad en poblaciones y de proponer estrategias de acción colectiva para mejorar la salud pública, separadas de escuelas de medicina cuya misión fuera la atención del paciente individual y la investigación del proceso de enfermedad. No obstante, el resultado fue más bien que las escuelas de medicina dejaron de interesarse en la epidemiología, las ciencias sociales y los métodos cuantitativos, aparte de que habiéndose limitado la misión de estas escuelas el contrato social entre el estamento médico y el público se fue anulando progresivamente y la medicina eventualmente se desatendió de los problemas y las necesidades de la población.

El otro componente de esta tercera tropelía, es decir la flexnerización de la medicina alopática también tiene como protagonista a la fundación Rockefeller, y además condujo a la hegemonía de tal tipo de medicina sin que ésta tuviera que mostrar una clara superioridad científica. De acuerdo a Chernomas, al cambio del siglo XIX al XX, los Rockefellers, Carnegies, Morgans y Huntingtons, comenzaron a poner mucha atención y a gastar millones de dólares en las escuelas de medicina y en la evaluación de la educación médica en general, incluyendo los consejos de educación estatales. Estas familias financiaron, entre 
otros estudios, una investigación acerca de las escuelas de medicina de los Estados Unidos y Canadá que condujo Abraham Flexner, un lego, pero hermano de Simón Flexner, el director del Instituto Rockefeller para Investigación Médica, a petición del presidente de la Fundación Carnegie.

La investigación consistió en la evaluación de sesenta y nueve escuelas de medicina, en setenta y ocho días de trabajo (cuando una de las formas de movilización más rápidas y al alcance de muchos era el tren), y resultó en el reporte Flexner que alcanzó al público casi de inmediato y contribuyó al cierre de muchas escuelas de medicina, sobre todo aquéllas que no eran alopáticas. Basándose en el reporte Flexner, los millonarios filántropos comenzaron a hacer contribuciones de acuerdo con sus estándares educacionales, cuya validez siempre fue cuestionada; sin embargo, sólo aquellos que se apegaban a tales estándares recibieron contribuciones y sólo quienes la recibían podían pagar el costo de los estándares que eran impuestos por ley y fueron establecidos por las fundaciones Rockefeller y Carnegie entre otras; estos estándares ${ }^{13}$ son apropiados para tratar de hacer contribuciones a la medicina y a la salud pública pero sin cambiar el status quo, y son los que han orientado la educación médica latinoamericana.

Aunque inseparable de las demás vejaciones articuladas y por articular en este escrito, esta clara intervención del estamento económico en asuntos de la salud que evoluciona a una estrategia colonizadora, puede reclamar la categoría de una cuarta tropelía contra la medicina y la salud pública.

Pero es necesario tomar en cuenta dos factores para acercarse al verdadero significado de la intervención de los capitalistas promoviendo lo que ha venido a ser la medicina científica moderna. Primero, que la teoría germen-enfermedad no fue la única teoría explicativa, ni se impuso por su calidad científica únicamente. Al menos, desde 1848, algunos científicos conocían que las condiciones sociales y económicas tenían un impacto crucial en la salud y la enfermedad y una sección de la profesión médica propuso el cambio en el pensamiento médico hacia lo que se llamó medicina social.

El segundo factor es más complejo. Con la aceptación de la atención médica y su legalización como otra mercancía; habiéndose aceptado el concepto de enfermedad como responsabilidad individual y la norma de atención de salud individual basada en el hospital, a raíz de biologizar y de "descontagiar" de lo social al concepto de la atención de salud; y dada la creciente preocupación de los capitalistas, particularmente de los industriales, por la salud de sus trabajadores en función de la productividad del proletariado, su presión al gobierno de los EE.UU. para que fundara hospitales se concretó de inmediato. 
Además, estos capitanes de industria financiaron la investigación y campañas masivas contra diversas enfermedades que afectaban a sus trabajadores y al público en general, con lo que se allanaba el camino para expandir sus negocios, se mejoraba la productividad, se creaba una imagen de empleador benefactor y se suprimía el malestar inherente a la relación de trabajo que era fuente constante de conflicto entre propietarios y trabajadores.

Esto está claramente ilustrado por la participación de la Fundación Rockefeller, establecida en 1913, en el control de la fiebre amarilla y de la malaria de la mano de los militares norteamericanos y por su campaña global de control de uncinarias, trabajando con Charles Wandell Stiles, destacado estudioso de tales parásitos. De hecho, ya en 1910 la Comisión Sanitaria Rockefeller había elegido el control de las uncinarias, los "gérmenes de la pereza", en el sur de los Estados Unidos, como una meta importante.

Cuando los países occidentales decidieron expandir su actividad económica hacia otros países, a través de la colonización en el siglo XIX; particularmente cuando los Estados Unidos decidió expandir tal actividad a Latinoamérica, a través del dominio sobre los países de la región dependiente del control militar y con el propósito de explotar los recursos de los países dominados, fundamentalmente adoptaron la estrategia que la organización
Rockefeller aplicó antes en el sur de ese país colonizador.

Ciertamente una vejación, pero también una excelente estrategia de dominación por colonización; una estrategia altamente eficiente, tanto que no es una exageración decir que la misma denuncia de ella como tal, puede provocar que incluso los mismos afectados por dicha tropelía-estrategia, señalen como ingrato, resentido social, rojo, o como comunista, idiota antineoliberal, etc., a quien hace o a quienes hacen la denuncia, porque mediante esta efectiva estrategia, los colonizadores o neocolonizadores han explotado a la población local de país tras país, pero construyendo simultáneamente una imagen de benefactores para ellos mismos, por la vía de proveer atención de salud para parcialmente contrarrestar problemas de salud, las más de las veces derivados directamente del mismo colonialismo.

Uno de los conceptos dominantes durante el apogeo de esta tropelía fue el que condujo a apostar a la erradicación de grandes enfermedades humanas y otro, el concepto relacionado de esfuerzos directos dirigidos (verticales) para mejorar la salud en los países subdesarrollados, los cuales tuvieron su campeón en la Fundación Rockefeller, organización que intentó la erradicación global de uncinariasis, fiebre amarilla y malaria.

El fracaso de estas estrategias condujo a otra tropelía, la cual debe 
ser conocida y comprendida como tal para entender la necesidad de realizar un cambio conceptual que pueda inspirar un plan congruente con la misión de mejorar significativamente la salud de los salvado- reños y de los latinoamericanos, lo cual pasa por universalizar la asistencia sanitaria en la región. Esta vejación es el nacimiento, desarrollo y fracaso de la Atención Primaria de Salud (APS).

\section{La nefasta alianza de dos atropellos parti- cularmente dañinos de la salud pública}

E sta vejación ocurre en el marco - de otro abuso que deberá ser conocido como la quinta tropelía en atención al orden cronológico; otro abuso que consiste en la intervención de bancos y otros organismos financieros en los asuntos de salud latinoamericanos y globales y que se traduce en la imposición de los programas de ajuste estructural a los países de la región, como expliqué antes.

Así, el nacimiento, desarrollo y el fracaso de la atención primaria de salud, sería la sexta tropelía contra la salud de El Salvador, América Latina y el mundo; estrategia, quizá paradigma, la cual, en realidad, nació muerta en 1978, porque, tal como apareció en la Declaración de Alma Ata, incluía la reorganización y la reorientación de los sistemas de producción y distribución de bienes y servicios como base para que sus elementos operativos fueran eficaces y eso simplemente nunca fue, nunca pudo ser.

Aunque, sin duda, la APS nació muerta, la forma en que se le presentó al mundo, su forma reducida, diferente, que en la práctica se iden- tificó como la Atención Primaria de Salud comprensiva, aún conservaba algo del carácter relativamente revolucionario de la propuesta original y exhortaba a cumplir los "elementos técnicos" básicos de ésta: educación en salud; control de enfermedades endémicas locales; programa expandido de inmunizaciones; atención materno-infantil, que incluye servicios de planificación familiar y promoción de la lactancia materna; disponibilidad de medicamentos básicos; promoción de la nutrición (vigilancia nutricional); y tratamiento ambiental, particularmente suministro de agua potable.

Es más, la estrategia vejada, ya en la forma de APS comprensiva, pudo ser presentada como la cara amable del resurgido liberalismo económico y servir de instrumento para paliar los efectos de los aspectos negativos del abuso.

No obstante, había más que soportar: entre finales de los setenta y principios de los ochenta, expertos en salud de alto nivel de los países industrializados le quitaron las alas a esta estrategia todavía reivindicativa, mientras sus auspiciadores $y$ 
seguidores todavía celebraban su advenimiento.

Los "realistas" y "objetivos" expertos argumentaron que, dados la recesión mundial y el recorte de presupuestos en salud, un abordaje como la APS comprensiva no sería costeable y, consecuentemente, se imponía enfocar los grupos de mayor riesgo (los más pobres de los pobres), para aplicarles unas pocas medidas costo-efectivas a través de una versión políticamente saneada de la estrategia original y de la APS comprensiva: la APS selectiva.

En otras palabras: menos para cada vez más pocos entre los más necesitados, cuyo número de integrantes puede, además, ser convenientemente manipulado de manera que, por ejemplo, si ahora los grupos de pobres están integrados por quienes viven con menos de dos dólares al día, mañana pueden estar integrados sólo por quienes viven con menos de un dólar al día y así sucesivamente.

Hasta UNICEF, fuerte defensora de la APS comprensiva, cedió ante la indiferencia de donantes y ministerios de salud y a la presión del clima socialmente retrógrado de los ochenta y propuso cuatro intervenciones como constituyentes de su versión de APS selectiva: control del crecimiento, inmunizaciones, amamantamiento materno y sales de rehidratación oral (GOBI, por sus siglas en inglés), como parte de su Revolución de Sobrevivencia de Niños, en realidad, un enfoque centrado en cuatro programas verticales.

Aunque UNICEF trató luego de ampliar el paquete limitado de tecnologías sanitarias con suplementos alimentarios, educación de la mujer y planificación familiar (GOBIFFF, por sus siglas en inglés), en la práctica, en la mayoría de países, la iniciativa de sobrevivencia de los niños quedó reducida a dos intervenciones: terapia de rehidratación oral e inmunizaciones.

La campaña de supervivencia de los niños recibió gran soporte a alto nivel y por parte de gobiernos, profesionales de la salud, USAID y hasta del BM, pero lo que dejó en claro es que intervenciones tecnológicas selectas no bastan para mejorar el indicador de mortalidad infantil, aumentar la calidad de vida o alcanzar la salud de los niños. Sea como sea, para principios de los noventa, la cobertura alcanzada por ambas intervenciones había disminuido en el ámbito mundial.

Por otra parte, la misma versión de algunos de esos expertos, incluso la versión de quien participó en la formulación de las propuestas vejadoras confirma lo anteriormente expuesto, pero también añade elementos que reafirman el carácter de tropelía perversamente instrumental de la estrategia de APS Ilevada a la práctica. De acuerdo con Kenneth S. Warren, un icono de la biomedicina, los expertos en salud se apoyaron en los expertos en economía para cortar las alas a la APS com- 
prensiva, puesto que poco después de la declaración de Alma Ata, en ocasión del reporte anual del BM, el presidente del mismo, Robert McNamara, sentenció que aún cuando se alcanzaran los crecimientos económicos más optimistas para el mundo en desarrollo, cerca de 600 millones de personas permanecerían atrapadas en pobreza absoluta para finales del siglo XX; por supuesto, manteniendo vigente e inalterable al sistema.

Sin embargo, en la opinión del autor del presente escrito, esa declaración del presidente del Banco Mundial, más que un argumento convincente contra la aplicación de la APS comprensiva -aunque de hecho haya servido para vejarla - señala que no importa lo que hagan los países dependientes, el contexto económico establecido no les permite superarse; aún cuando la intención de ellos sea superar lo que en las palabras del mismo presidente del Banco Mundial de aquella época es la pobreza absoluta "una condición de vida tan caracterizada por mal nutrición, analfabetismo, enfermedad, alta mortalidad infantil y baja esperanza de vida como para estar debajo de toda definición razonable de decencia humana". Se dice que más bien eso es lo que señala la declaración de $\mathrm{McNa}$ mara, porque entre otras cosas, el contexto presente aún incluye una economía y un comercio inequitativos y propiciadores de iniquidad y a un Banco Mundial con mayor injerencia en asuntos de salud y pobreza al menos desde 1993. Otra vez resulta conveniente separar las lágrimas del cocodrilo.

De hecho, en el presente el BM, partícipe de la estrategia neoliberal de superación de la pobreza, y en el marco del pleno desarrollo de la iniciativa de los objetivos del milenio, pronosticó la probable generación de tres mil millones de nuevos pobres entre el 2003 y el 2050 (a un ritmo probable de 63.8 millones de nuevos pobres por año) mientras la población mundial crece a un ritmo de aproximadamente ochenta millones por año casi en su totalidad en los países subdesarrollados; es decir, el BM advierte el evidente fracaso de las estrategias de reducción de la pobreza.

Aunque Warren refuerza su versión citando documentos publicados en 1986, los cuales incluían cálculos de la enormidad de los costos de la política de "salud para todos" y concluían que sus metas no tenían la relación deseada con los recursos, es decir, indicaban el carácter inasequible de la propuesta, el argumento económico entre los citados por Warren que pudo haber tenido influencia a fines de los años setenta, es el del presidente del Banco Mundial de entonces.

Esto es más importante de lo que parece, porque, entre otras cosas, el argumento de Warren continúa con que como no podían esperar a que se llegara a la afluencia, la alternativa era hacer algo basándose en datos de incidencia, prevalencia, 
morbilidad, mortalidad, factibilidad de control y en datos de costos, tomando en cuenta lo concerniente a equidad, efectividad y economía; y además, porque prosigue señalando que en el desarrollo de esta nueva forma de abordaje dos nociones jugaron un papel crítico. El concepto basado en las ciencias de la población relacionado con el programa de acción intersectorial para la salud de la OMS que se había desarrollado en el tercer mundo y que había demostrado ser una forma efectiva de proveer salud a bajo costo y sobre todo, el concepto biomédico de atención primaria selectiva, APS selectiva en su forma abreviada, que como ya se señaló pretendía mejorar la salud en muchas partes del mundo subdesarrollado aplicando únicamente cuatro medidas verticales. Vale la pena destacar que además, el concepto de APS selectiva partió del argumento de que la mejor manera de mejorar la salud es combatir la enfermedad, basándose en intervenciones médicas costo-efectivas.

Los proponentes de la nueva estrategia sostenían que hasta que la APS comprensiva pudiera estar disponible para todas las personas, la APS selectiva podía ser la mejor medida para mejorar a mayor número de personas, y aunque es de reconocer que se le presentaba como una medida provisional, la historia demostró que el programa en vez de ampliarse en la práctica se redujo y más bien tomó la forma de la iniciativa de sobrevivencia de los niños de UNICEF. El proponente de la APS selectiva, todavía en 1988 celebraba la "expansión" del programa de sobrevivencia de los niños, y lo presentaba como un programa que pasaba los límites de las inmunizaciones y que tenía a la planificación familiar y a la rehidratación oral como sus principales estrategias.

De hecho, Warren, en 1988, concluía un artículo calificado de histórico, en el que señalaba que el poder de la investigación biomédica, concatenado con la aplicación de sus resultados es esencial para el bienestar de ambos el mundo desarrollado del norte y el mundo subdesarrollado del sur, pasando por alto toda la evidencia que el mismo artículo contenía a favor de la importancia de lo social para el logro de la salud en las poblaciones.

En efecto, el autor elegía la solución biomédica, cuando ya era evidente para él que las medidas aplicadas no disminuían el problema que pretendían combatir, puesto que reconocía que gran parte de la población de los países subdesarrollados se encontraba bajo el inaceptable e insoportable signo de la pobreza, la malnutrición y las enfermedades infecciosas. Optaba por dicha solución cuando también era evidente para él que la transición de salud obligaba a enfrentar una carga de enfermedad en los países subdesarrollados, sobre la cual las medidas del tipo de la APS selectiva o las del tipo de la APS comprensiva 
no tenían ni podían tener efecto directo alguno; optaba por la solución biomédica, es decir por otro modelo selectivo enfocado a la enfermedad, cuando en su mismo artículo histórico, destacaba que en 1986 ya era evidente que el listado de las diez principales causas de muerte anuales en los países subdesarrollados incluía a las enfermedades del sistema circulatorio, como sólo segundas a las infecciones agudas de las vías respiratorias (IRAS) y no por mucho; así como a las lesiones, éstas en un cuarto lugar compartido con el sarampión, y en un quinto o sexto lugar a los neoplasmas; todas ellas consideradas entidades no infecciosas en términos generales, que para entonces constituían, en conjunto, un $36.1 \%$ de la mortalidad generada por las diez primeras causas de muerte de esos países, quienes además debían enfrentar la problemática con insuficientes recursos.

El autor elegía a la biomedicina y a los paquetes básicos de salud en 1988, cuando ya en 1986, con base en los datos citados en el párrafo anterior, las cifras de las cinco primeras causas de muerte en los países subdesarrollados podrían haberse reportado así: IRAS 10 millones; enfermedades del sistema circulatorio 8 millones; diarreas 4.3 millones; sarampión y lesiones 2 millones cada entidad y neoplasmas 1,7 millones, para un total anual de 28 millones de muertes y un $41.8 \%$ de ellas debido a entidades no infecciosas. $Y$, finalmente, el autor hacía la elección a pesar de que no discutía que la carga de enfermedad de los países subdesarrollados tuviera su origen en el deterioro medioambiental, la disrupción social y la pobreza prevalecientes en ellos; y pese a que reconocía el valor de la evidencia de que aún con todos los problemas que convergían en ellos, cuando en los países subdesarrollados se unían una decisión política y social favorable a la equidad, la distribución y el acceso equitativos a la atención de salud según la necesidad, el acceso uniforme al sistema educacional y la disponibilidad de nutrición adecuada a todos los niveles (seguridad alimentaria) sin inhibir la producción agrícola indígena, se podían alcanzar grandes logros en salud, tal como lo demostraban las experiencias de Cuba, Costa Rica, el Estado de Kenala y Sri Lanka.

Como era de esperarse, el modelo selectivo no ha respondido adecuadamente, de manera particular a la relación entre salud y desarrollo económico. Esto es cierto aunque se argumente, incluso con base, que hay grandes progresos en cobertura de vacunación, reducción de la mortalidad infantil y en el incremento de la esperanza de vida; esto es cierto, como también es verdad que aunque por una parte se pueda sostener que, entre 1985 y 1993, el número de niños menores de cinco años que morían por enfermedades previsibles mediante vacunación disminuyó en 1.3 millones, por otra parte, es posible asegurar 
que en ese mismo período murieron 2.4 millones de niños menores de cinco años debido a las llamadas enfermedades previsibles por vacunación, así como que, actualmente en los países subdesarrollados, la diarrea infantil y la desnutrición contribuyen mucho a la morbilidad de sus poblaciones y también a la muerte de los 13 millones de niños menores de cinco años que mueren anualmente.

No puede ser de otra manera, porque la APS selectiva se orienta por el concepto de salud como ausencia de enfermedad; dado que es un abordaje tecnocrático que se aleja del requerimiento del cambio en el estatus socio-económico y en la distribución de recursos para el desarrollo de la salud; puesto que enfoca la enfermedad pero no el contexto; y porque los elementos constituyentes de la medida se aplican sin coordinación alguna, propiciando redundancias, traslapes y desperdicios y se limita a enfocar grupos selectos — principalmente mujeres y niños - en detrimento de otros grupos que también enferman.

\section{Dos atropellos descarados fundamentados en conceptos atropellados, aunque hábilmente presentados}

S in embargo, encontramos algunas vejaciones más: una de ellas, la que vendría a ser una séptima tropelía, es la combinación de la modernización global con la toma de liderazgo por parte del Banco Mundial en la planificación de las políticas de salud para los países subdesarrollados; otra, una octava tropelía, la representada por la combinación de las estrategias de presionar por la reorientación de las funciones esenciales de la salud pública (FESP) y de reconceptualizar la salud, la enfermedad, y los indicadores de salud, contenidas en la iniciativa La salud pública en las Américas, de la OPS/OMS.

Creo que esta séptima vejación es de lo que ha tratado la mayor parte de este escrito hasta ahora; sin embargo, cabe puntualizar un par de cosas en relación con ella. Primera, que comprender esta vejación en su naturaleza y propósitos, reconocer a sus autores, actores y relaciones, en resumen conocer su realidad, es crítico para comprender las determinantes y las tendencias de las crisis de las ciencias de la salud y de los sistemas sanitarios en nuestros países. Segunda, que su presencia indica que el capitalismo se siente tan libre y seguro que actúa con descaro.

Denunciar la octava tropelía no es un innecesario irrespeto a la OPS/OMS o un ejemplo de derribo de muros cuando se pueden abrir puertas; tampoco se trata de señalar 
un problema enteramente nuevo, pero sí, uno con el potencial de sorprender a quien supone que los sistemas de salud y las organizaciones internacionales de salud están fuera de la aldea global y no deben obedecer los lineamientos del poder. No, no es así. Al igual que otras organizaciones internacionales gubernamentales la OPS y la OMS dependen del respaldo financiero y político de los gobiernos y consecuentemente, es susceptible de persuasión por parte de ellos y de sus instrumentos de persuasión tales como el BM, FMI, el Banco Interamericano de Desarrollo (BID), USAID, etc. Al menos en gran medida ésta es la razón por la cual la OPS/OMS aceptó y abonó a los abusos Ilamados APS comprensiva y APS selectiva; por la que contribuyó en 1993-1994 con el infame informe ANSAL, privatizador e irresponsable; así como la razón por la que colaboró con la guía básica de la reforma neoliberal en el ámbito global, es decir, el informe del BM Invertir en Salud de 1993, todo esto a pesar de ser una organización protectora de la salud.

Además, tal como lo plantean Gwatkin y colaboradores hay una ley que ha funcionado por más de treinta años, la cual establece que "la disponibilidad de buena atención médica tiende a variar inversamente con la necesidad que tenga de ella la población servida", o sea la ley de la atención a la inversa, cuya operatividad es corroborable en el presente y que desafía a la máxima de que los más necesitados debieran recibir mayor y más frecuente atención. De manera que la pregunta es: ¿qué hicieron la OPS y la OMS para evitar su aplicación?

Sin embargo, tampoco esto es un problema de querer creer o no; es, más bien, que la tropelía denunciada es la esencia del planteamiento de la iniciativa La salud pública en las Américas, de la OPS y la OMS, presentada el 2002.

En efecto, pese a consignar en sus escritos que "la reforma de los sistemas de salud constituyen un fenómeno mundial, influido por la ideología del mercado, la limitación de los recursos y las recomendaciones de instituciones financieras internacionales como el Banco Mundial y el Fondo Monetario Internacional", la OPS/OMS plantea que la reforma del Estado y la centralización de la vida política, económica y social de los países, así como las reformas del sector salud exigen fortalecer la función rectora de las autoridades sanitarias nacionales (ASN) y que una parte importante de tal función es hacer cumplir las FESP. Sin embargo, además explica que el avance en la descentralización del Estado y del sector salud $y$ el surgimiento de otros autores públicos y privados, están determinando que la provisión de los servicios, sobre todo los que tienen que ver con la atención a las personas, tienden a dejar de ser una responsabilidad directa de los ministerios nacionales de salud; $y$, removiendo cualquier duda, continúa explican- 
do que algo similar acontece con la provisión de servicios de salud pública y con la ejecución de acciones de regulación sanitaria que tienden a ser asumidos por las instancias intermedias (estados, departamentos o provincias) o locales (municipios y cantones) del Estado.

Con ello, la OPS/OMS, no sólo no descubre y menos modifica la esencia neoliberal y privatizadora de las iniciativas de reforma, sino que sienta las bases para el impulso más efectivo aunque sutil a la privatización de los sistemas públicos de atención médica individual.

Esto es así porque, entre otras cosas, dentro de las once nuevas funciones esenciales de la salud pública elaboradas y promocionadas por la OPS, altamente coincidentes con las que contiene la propuesta del Programa Nacional de Desempeño y Estándares de la Salud Pública (NPHPSP) de los EUA y con las funciones definidas por el estudio Delphi de la OMS, no se incluye la organización de servicios dirigidos a la atención curativa individual porque de ellas se excluye la prestación y/o el financiamiento de la atención curativa individual.

Además, porque la pregunta obligada es, entonces, ¿qué sector dentro del sistema económico dominante deberá asumir la organización y la prestación de los servicios curativos individuales, si, al ya no ser estas funciones esenciales del sector público, éste ya no asume la tarea? No hay dónde perderse porque no hay otra alternativa: ¡el sector privado!

No importa que OPS/OMS plantee el hacer cumplir las FESP como una reivindicación, como la reinclusión de la salud pública en el programa de transformación del sector, la exclusión de la prestación y el financiamiento de la atención curativa individual o la atención de las personas de la lista de FESP es privatización, y es además, una tropelía a la salud de las mayorías.

La OPS/OMS continúa diciendo: "La visión de la salud pública debe ser, por consiguiente, el criterio principal para la conformación, rectoría y gestión de los sistemas de salud". Sin embargo, como se señaló antes, es claro que para esta organización de salud las acciones de salud pública y las acciones de atención individual de salud son cosas distintas, aunque puedan ser complementarias.

Pero también, y con mayor grado de peligrosidad para la seguridad de la salud pública, la OPS/OMS establece los fundamentos de la renovación conceptual que es parte de la iniciativa La salud pública de las Américas, basándose en el siguiente planteamiento: "la salud pública es entendida como la salud del público, de la población, y abar$\mathrm{ca}$, por tanto, todas las dimensiones colectivas de la salud. Esta noción de salud pública nace del mismo concepto de salud, concebida como la ausencia de enfermedad, de lesiones y de incapacidad, en 
un completo estado de bienestar. Sin embargo, la identificación de la salud con el bienestar plantea dificultades operativas para delimitar las responsabilidades del sector de la salud, al mismo tiempo que establece la responsabilidad de los otros sectores en la salud y la necesidad de actuaciones intersectoriales. En un sentido más sectorial y operativo, la salud es la realización del potencial bio-psíquico de las personas y de las poblaciones de acuerdo con las diferentes circunstancias en las que viven, sin limitaciones por lesiones, incapacidad o enfermedad $y$, en el caso de que estas ocurran, con la posibilidad de contar con la pronta recuperación o la adecuación funcional en las situaciones de discapacidad irreversible" ${ }^{\prime 14}$.

En otras palabras, reconceptualizar la salud en función del neoliberalismo, las acciones de salud pública con orientación bio-psíquica y la negación de uno de los mayores aportes de la OMS a las ciencias de la salud: su famosa definición incluyente de lo físico, o mental y de lo social en el concepto de la salud.

Por supuesto, la nueva iniciativa de OPS/OMS también es una propuesta de volver al biologismo reduccionista y a la falsa dicotomía individual/colectivo, ya superados conceptualmente en el ámbito de las ciencias de la salud por la propuesta documentada en la que destaca la noción que califica la separación entre lo individual y lo colectivo y a la noción de la separación entre lo social y lo natural o biológico como falsas dicotomías; por la propuesta que también claramente plantea la esencial unidemensionalidad de los procesos salud/enfermedad en tanto colectivos y socionaturales, relegando a los "casos individuales" de enfermedad y de salud a expresiones episódicas carentes de autonomía con respecto al proceso socionatural/colectivo más amplio. Lo cual, por supuesto, implica negar que los casos individuales de enfermedad o de salud son o pueden ser expresiones biológicas de fenómenos sociales más amplios y más bien implica rescatarlos como procesos socionaturales y como parte de la colectividad; además de que exige negar que la enfermedad y la salud colectivas son procesos en los cuales aquello que es supuestamente biológico a nivel individual se transforma en social a nivel colectivo y exige rescatarlas como procesos unidimensionales, colectivos y socionaturales en toda la línea de su desarrollo.

¿Estaremos asistiendo al nacimiento de una nueva medicina sin corazón y al de una nueva salud pública sin salud para el público, en el marco de un consumismo alentado por la concupiscencia desmedida? 


\section{La alianza perversa a nivel molecular}

a última tropelía a la que me referiré es la que Helfrich y Villarreal Ilamaron la "alianzain-santa" biotecnológica, la que se produce "entre el desarrollo y patente de la tecnología computarizada con los avances en la ingeniería genética aplicada a todo lo vivo", de la cual

\section{Cierre}

N o es posible obviar que en particular en los países dominados, el curso de los eventos dependerá de la atención que se le preste a la pregunta sobre si puede la gente ser saludable en un mundo enfermo, dentro de un medio ambiente sometido a explotación torpe y abusiva; así como dependerá de los esfuerzos conducentes a modificar la tendencia hacia el fortalecimiento de la nefasta alianza entre el desarrollo y patente de la tecnología computarizada con los avances de la ingeniería genética aplicada a todo lo vivo, la cual persigue la privatización de la vida y del conocimiento.

Termino aquí aunque haya más temas que tratar y más que decir acerca de los que he discutido, porque, por una parte, creo que quien desee entender ya ha sido expuesto a suficientes argumentos y hechos como para sacar sus conclusiones derivan tanto un mundo patentado, como la privatización de la vida y del conocimiento. Es decir, la transmutación de la misma vida humana en mercadería desde lo más íntimo, la más tecnologizada expresión del desmedido apetito por los bienes terrenales, inspirada en el neoliberalismo.

o para informarse más y decidir. $Y$ porque, por otra parte, ningún argumento adicional cambiará posturas de aceptación de esta situación adversa de salud por conformismo, fatalismo o realismo paralizante, motivos que para muchos resultan menos dolorosos o difíciles que los esfuerzos necesarios para cambiar la situación adversa. Ningún otro argumento cambiará posturas de aceptación por conveniencia tampoco. Después de todo, en nuestra cultura política-social, tan ligada al hecho de que en la práctica parece ser más conveniente apegarse al poder que a la ley, prevalecen consejos tales como "no te metas" o "el que anda de redentor termina crucificado" los cuales, ante los resultados usuales parecen ser consejos sabios, aunque, al observarlos cuidadosamente, más reflejen la situación que probablemente quiso describir Sigmund Freud diciendo "existen dos maneras de ser feliz en 
esta vida: una es hacerse el idiota y la otra es serlo".

\section{Agradecimientos:}

El autor desea agradecer de manera especial al Padre Francisco Javier Ibisate, S.J., por el incentivo que representa su generosa revisión del mismo, a la Dra. Nuria Homedes por sus observaciones y comentarios

Notas

1 Es casi innecesario decir que también hay un gradiente entre el ingreso disponible y la posición social.

2 Eso tuvo lugar entre 1950 y 1970 en los países hegemónicos, con base en promedios de tres años. En los países dependientes, el PIB correspondiente fue 1.7.

3 Conocido como BM, pero llamado originalmente Banco Internacional para la Reconstrucción y el Desarrollo.

4 La crisis consiste en: el fin del capitalismo de bienestar y del fordismo ante el alza de los precios del petróleo y los cereales y el estancamiento económico de los años 70; la conversión del gobierno en "empresa privada", orientado hacia el mercado y la eficiencia, así como en la presión a las empresas para producir desde unidades mucho más pequeñas y flexibles; ajustes estructurales y endeudamientos irracionales cada uno de ellos con sus propias crisis; amenazas de depreciaciones catastróficas; que enriquecieron este documento, al Dr. Sergio A. Cañas López por la lectura crítica del artículo, y a todas aquéllas personas que como el Dr. José Héctor Paz me alientan a escribir y me ayudan constantemente a fortalecer mis ideas con su generoso aporte de información, observaciones y sugerencias.

2 de febrero de 2007.

más ajustes estructurales cada vez más penosos, etc., ocurridos en los años 70 y 80 . El colapso de Bretton Woods en 1973, atribuible en gran parte a la incapacidad de los EE.UU. de conducirse de acuerdo con las reglas de comportamiento monetario internacional que él mismo había establecido es central en la crisis, puesto que desde entonces la norma para la mayoría de países industrializados ha sido una combinación de producción lenta, reducción de los salarios reales, desigualdad en el ingreso, precariedad de empleos y desempleo. Para los países subdesarrollados la tónica ha sido similar, agravada sin embargo, por una mayor vulnerabilidad conducente a la profundización de las iniquidades y por el abandono económico. Además, en un marco de sobrecarga ecológica - que señala límites a la fuerza vital del capitalismo: el aumento constante de la escala de producción- la norma se ha caracterizado por la conexión incrementada entre los mercados de muchos países, la cual se expresa en un enorme aumento de la movilidad del capital que presenta tanto el aspecto de la globalización de la producción, como 
el de la globalización de las finanzas. La norma tampoco es general, estas características "positivas" de la globalización afectan sólo a los países desarrollados y a un reducido grupo de países subdesarrollados. Además, la enorme movibilidad del capital no es desligable del impulso capitalista de lucrarse y de acumular en pocas manos - de manera legal o ilegal, aunque siempre de forma injusta- expresado en desigualdades inaceptables (el ingreso del 1\% más rico de la población mundial es igual al del 57\% más desfavorecido de la misma) y en la aparición de más capitales de los que el sistema puede absorber para invertirlos en producción, así como en la necesidad de invertirlos especulativamente; y como resultado de ello, expresado también en la exigencia de privatizar y de convertir todo el hacer humano en espacio de realización de capital y en la transformación de la sociedad en un proceso de violencia estructural y de horror social. Como señaló Farmer, el antropólogo de Harvard, en 2005, en estas circunstancias el mismo derecho de sobrevivir de muchos es pisoteado en una era de gran afluencia que favorece a muy pocos y la economía de mercado globalizada lejos de cumplir promesas de equidad, produce marcados excesos a la par de grandes miserias, debido al incremento de la acumulación de la riqueza.

Por otra parte, no es posible negar el poder "de hecho" de la globalización: su impresionante influencia en la construcción de la sociedad económica actual y venidera, debida a que el capitalismo es el sistema económico dominante en la mayor parte del mundo, principalmente como consecuencia del colapso económico de la Unión Soviética y del consecuente fenómeno de arrastre hacia el mercado y la privatización que sufrieron países que aplicaban estrategias socialistas entonces. $\mathrm{Ni}$ China pudo escapar de ello, tampoco de la seducción del flujo de inversiones; sin embargo, aunque la China urbana sea el área de más rápido crecimiento económico en el mundo, difícilmente el país puede ser ejemplo de éxito capitalista. El problema es que la asimetría de poder puede generar brutalidad silenciosa y que desigualdades de poder impiden la distribución equitativa de oportunidades y pueden arruinar las vidas de quienes no están en control de los procesos, tal como lo ha planteado Amartya Sen. Además, en este sentido, Farmer argumenta y documenta que las violaciones a los derechos humanos no sólo no son accidentes, sino síntomas de patologías del poder íntimamente ligadas a condiciones sociales. Crisis del capitalismo, también porque a pesar de esta posición dominante su predominio futuro parece depender más de su flexibilidad que de su ortodoxia.

5 ¿Qué habría sido de la economía salvadoreña con la crisis del café y sin migraciones ni remesas que la amortiguaran?

6 Otra brillante pieza ideológica neoliberal. ¿Estará exenta de externalidades la atención médica individual de la cabeza de la familia que sufre enfermedad cardiaca coronaria prematuramente? ¿Lo afecta sólo a él o también a quienes dependen de él o ella? iObvio! ¿Verdad?

7 Las contribuciones de los usuarios provendrían también de diversas 
fuentes: los empleados afiliados al ISSS contribuirían a través de impuestos a la planilla, IVA, renta y contribuciones del bolsillo (rubro de medicinas); los patronos afiliados al ISSS con impuestos a la planilla, renta, IVA y con aportes del bolsillo tanto para medicinas como por los pagos al seguro; patronos $y$ trabajadores informales con IVA y del bolsillo; los atendidos vía MSPAS con IVA quizá renta y del bolsillo.

8 A diferencia de Salomón, los sabios locales usualmente parten al "niño" en dos, tratando así de quedar bien con todos.

$9 \quad$ Único en oposición a fragmentado en diversas dependencias públicas y a mixto, público y privado, así como por ser responsabilidad directa del Estado. No en el sentido de ser sustituto del sector privado.

La idea de producir localmente los medicamentos básicos que se necesitan en El Salvador puede parecer descabellada y hasta temeraria, no así la de apoyar un esfuerzo de producción regional (un mercado latinoamericano) de los mismos. Sin embargo, lo crítico es encontrar alternativas al régimen de patentes por injusto $\mathrm{y}$, en algunos aspectos, ineficiente, precisamente ahí donde ese sistema clama ser eficiente. Después de todo, una comisión creada por la OMS opina que dicho régimen perjudica a los países pobres y otros investigadores como Baker han documentado que, en el peor de los casos, optar por un monopolio público conduciría a ahorros que el monopolio privado no puede ofrecer, aunque se incurriría en desventajas similares a las que presenta la otra opción.

Tanto medicamentos de marca como genéricos, esenciales, naturales, etc.

12 Tan predominantemente que otros problemas de salud resultan insignificantes.

13 Uniformidad de curricular, fundamentada en ciencia de laboratorio (ciencias básicas) y enseñanza clínica (ciencias clínicas), con énfasis en la voluntad de retomar y cambiar a la nueva forma de medicina fundamentada en el laboratorio y en la teoría de germen-enfermedad. La Escuela de Medicina de la Universidad de John Hopkins es el modelo de escuela.

14 Las cursivas de este párrafo son nuestras. 